\title{
Utilization of salts of volatile fatty acids by growing sheep
}

\section{5.* Effects of type of fermentation of the basal diet on the utilization of salts of acetic acid for body gains}

\author{
By D. A. POOLE† AND D. M. ALLEN $\ddagger$ \\ Department of Agriculture, University of Reading \\ (Received 27 October 1969-Accepted 26 February 1970)
}

\begin{abstract}
I. An experiment is reported in which groups of six lambs were fed two basal diets supplemented at three levels with a mixture of sodium and calcium acetates.

2. The basal diets were given in amounts that provided equal intakes of digestible organic matter and crude protein. One contained $85 \%$ of concentrates $(\mathrm{Hc})$, the other $40 \%$ of concentrates (Lc). Rumen contents from a sheep receiving diet Hc contained a lower molar proportion of acetate and higher proportions of propionate and butyrate than when diet Lc was given.

3. The calculated metabolizable energy of the basal $\mathrm{Hc}$ diet was utilized more efficiently than that of the basal Lc diet, for promoting empty body-weight and carcass-weight gains.

4. On both basal diets, lambs receiving the diets supplemented with acetate made greater live-weight, empty body-weight and carcass-weight gains than lambs given unsupplemented diets. The responses of weight gain to increasing levels of acetate were linear.

5. The responses to acetate were greater when it was given with the Hc diet than with the Lc diet. This effect was most marked for live-weight gain $(P<0.001)$, intermediate for empty body-weight gain $(P<0.05)$, but not significant for carcass-weight gain. This order of effects was in part due to a greater weight of alimentary tract tissue, and its contents, in lambs fed the Hc diet supplemented with acetate.

6. It is concluded that under certain circumstances the energy of acetate may be utilized less efficiently than energy from propionate or butyrate.
\end{abstract}

Conflicting results have been recorded from experiments in which the utilization of acetate for growth has been compared with that of propionate or butyrate. Armstrong \& Blaxter (1957) and Armstrong, Blaxter, Graham \& Wainman (1958) found that when acetic acid was infused into the rumen of sheep, its utilization for lipogenesis was less than that of propionic or butyric acid. Poor utilization was associated with a high heat increment, some of the reasons for which were indicated by McClymont (1952).

In previous experiments of this series where salts of volatile fatty acids (VFA) were fed to growing lambs, Ørskov \& Allen (1966 $a, b, c)$ and Ørskov, Hovell \& Allen (r966) found no differences in the efficiency of utilization of energy from salts of different

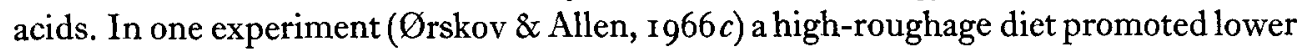
weight gains than a high-concentrate diet; associated with this effect was a greater molar proportion of acetic acid in the rumen liquor of lambs fed the high-roughage diet. It was postulated that the poorer utilization of energy in this experiment might be associated with losses of energy in the formation of acetic acid rather than in its subsequent utilization.

\footnotetext{
* Paper no. 4: Br. F. Nutr. (1966), 20, 5 I9.

$\dagger$ Present address: Trawscoed Experimental Husbandry Farm, Aberystwyth, Cardiganshire.

I Present address: Meat and Livestock Commission, Bletchley, Bucks.
} 
In the experiment reported here we studied the utilization of salts of acetic acid, added at three levels, to two basal diets which were known to induce different patterns of rumen fermentation. Addition of acetate at three levels made it possible to apply the more refined statistical method of linear regression analysis to the experimental results.

\section{EXPERIMENTAL}

\section{Animals and facilities}

Fifty-four Clun Forest and Suffolk $\times$ Clun Forest wether lambs were weaned off grass at $I_{3}-15$ weeks of age when they had a mean live weight of $28 \mathrm{~kg}$. They were housed in individual pens with self-cleaning floors in a building with forced ventilation.

\section{Design and treatments}

After a period of 4 weeks during which the lambs were accustomed to dry feed, they were grouped into six blocks, each block containing nine lambs of similar live weight. Within each block, lambs were allocated at random to nine treatments as follows: initial slaughter group; basal high concentrate $(\mathrm{Hc})$ with ( $15 \%$ hay and $85 \%$ concentrate); $\mathrm{Hc}+228 \mathrm{kcal}$ acetate $/ \mathrm{d} ; \mathrm{Hc}+456 \mathrm{kcal}$ acetate $/ \mathrm{d} ; \mathrm{Hc}+684 \mathrm{kcal}$ acetate $/ \mathrm{d}$; basal low concentrate (Lc) (60\% hay and $40 \%$ concentrate); Lc $+228 \mathrm{kcal}$ acetate $/ \mathrm{d}$; $\mathrm{Lc}+45^{6} \mathrm{kcal}$ acetate $/ \mathrm{d}$ and $\mathrm{Lc}+684 \mathrm{kcal}$ acetate $/ \mathrm{d}$.

\section{Digestibility trials}

Before the main feeding experiment, the digestible organic-matter contents of the hay and the two basal concentrates were determined in vivo. Eight mature wethers were harnessed, fitted with faecal collection bags and housed in digestibility crates.

Table I. Digestibility of organic matter $(\%)$ in the two diets, determined with four sheep for the complete diet and with eight sheep for the hay

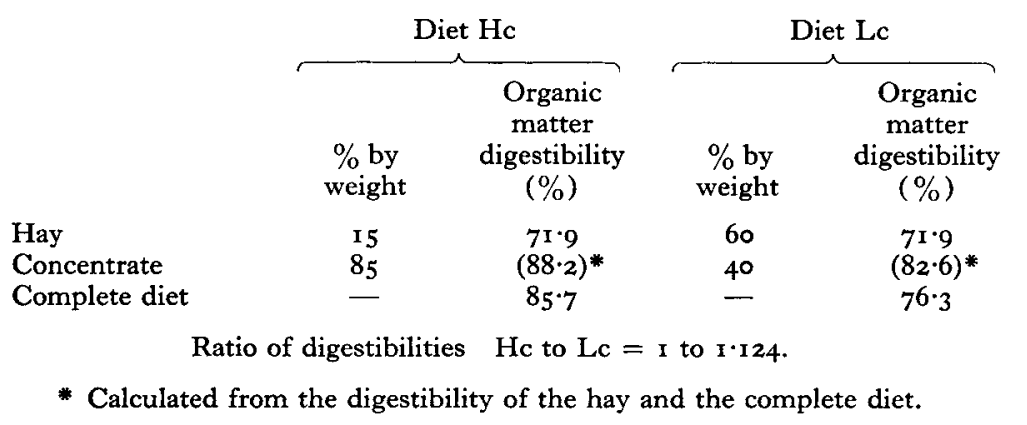

They were first fed the hay, and subsequently each basal diet was fed to a group of four wethers. The diet under test was always fed for a preliminary period of Io $\mathrm{d}$ and a collection period of 7 d. Faeces were dried to constant weight at $100^{\circ}$ and the organicmatter contents of the feeds and faeces were determined by the method listed in the Fertilizer and Feedingstuffs Regulations (Great Britain: Parliament, 1960). The results are presented in Table $\mathbf{I}$. 
The results of the digestibility trial were used to calculate the level of feeding of each basal diet which would provide equal intakes of digestible organic matter.

\section{Composition and preparation of diets}

The hay was of good quality, being made from a predominantly perennial ryegrass sward, cut at the flowering stage. It was chopped into approximately $2.5 \mathrm{~cm}$ lengths before feeding.

The basal diets were fed in quantities sufficient to provide equal intakes of digestible organic matter. Having decided on these quantities, the level of crude protein in each concentrate was adjusted so that the lambs also had equal intakes of crude protein. The composition of these concentrates is shown in Table 2. The rather high crude protein content of $18 \%$ was adopted so that liberal quantities of protein would be available to balance the supplementary energy derived from acetate.

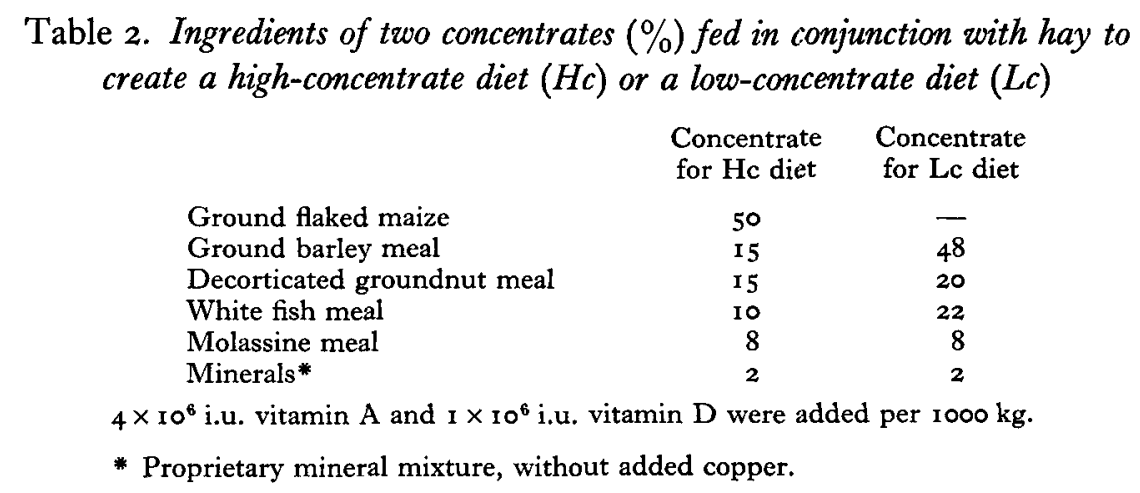

Acetate salts were incorporated into the concentrates. To minimize the possible adverse effects of a single metallic ion, a I to I weight for weight mixture of sodium and calcium acetate was used. The amount of acetate incorporated into the concentrates was verified by chemical analysis.

All the concentrates were cubed using a ${ } \cdot 5 \mathrm{~cm}$ die, although cubing was difficult with those concentrates containing high levels of acetate.

\section{Management of lambs}

The rations were weighed daily, approximately two-thirds being offered at 17.00 hours and the remainder at 09.00 hours. Uneaten food, if any, was removed daily and dried to constant weight. Most food refusals occurred soon after the start, so that it was possible to give the lambs an equivalent amount of food later in the experiment, by making additions to the daily ration. Water was offered ad lib.

The lambs were weighed to the nearest $0.25 \mathrm{~kg}$ on 3 consecutive $\mathrm{d}$ in alternate weeks, and mean live weights were calculated. At this time, the food allowances for lambs in each block were recalculated, according to the adjusted live weight of the control lamb which received the basal Lc diet. The adjusted live weight was computed by adding the mean gain of all the control lambs to the live weight of the control 
lamb in each block which had been recorded 2 weeks previously. This adjustment reduced the immediate effect of abnormal weight gains by an individual lamb.

To achieve a moderate growth rate in unsupplemented lambs, a level of feeding equivalent to I $3 \mathrm{~g}$ of basal Lc diet per $4.5 \mathrm{~kg}$ live weight was chosen. Lambs receiving supplemented diets were offered an amount which contained the same amount of basal concentrate in addition to the acetate supplement. Over the whole experimental period the average intake of the basal Lc diet was $775 \mathrm{~g} / \mathrm{d}$. Calculated mean daily intakes of metabolizable energy from the basal diets and acetate supplements are shown in Table 3 .

Table 3. Mean daily intakes of metabolizable energy $(M E)$ (kcal/d) calculated from the intended levels of feeding to groups of six lambs receiving a high-concentrate $(H c)$ or a low-concentrate $(L c)$ diet, with or without acetate supplementation

\begin{tabular}{|c|c|c|c|c|}
\hline Diet & Hay* & Concentrate $\uparrow$ & Acetate $\ddagger$ & Total \\
\hline Hc unsupplemented & 228 & 1619 & - & 1847 \\
\hline $\mathrm{Hc}+228 \mathrm{kcal}$ acetate $/ \mathrm{d}$ & 228 & 1619 & 228 & 2075 \\
\hline $\mathrm{Hc}+456 \mathrm{kcal}$ acetate $/ \mathrm{d}$ & 228 & 1619 & 456 & 2303 \\
\hline $\mathrm{Hc}+684 \mathrm{kcal}$ acetate $/ \mathrm{d}$ & 228 & 1619 & 684 & 2531 \\
\hline Lc unsupplemented & 1032 & 815 & - & 1847 \\
\hline $\mathrm{Lc}+228 \mathrm{kcal}$ acetate $/ \mathrm{d}$ & 1032 & 815 & 228 & 2075 \\
\hline $\mathrm{Lc}+45^{6} \mathrm{kcal}$ acetate $/ \mathrm{d}$ & 1032 & 815 & $45^{6}$ & 2303 \\
\hline $\mathrm{Lc}+684 \mathrm{kcal}$ acetate $/ \mathrm{d}$ & 1032 & 815 & 684 & 2531 \\
\hline
\end{tabular}

The health of the lambs was generally good. One suffered from foot rot on two occasions, but in both instances the condition responded to treatment with a tincture of chloromycetin. Some mild scouring occurred which proved to be contagious; those lambs receiving large supplements of acetate appeared to be particularly prone to infection. The scouring was controlled following a subcutaneous injection of $10 \mathrm{ml}$ of $33.3 \%(\mathrm{w} / \mathrm{v})$ sodium sulphadimidine solution (Day, Son \& Hewitt Ltd).

\section{Slaughter procedure}

The initial slaughter group was slaughtered at the beginning of the experiment, the remaining groups being slaughtered over a period of $3 \mathrm{~d}$ after 98,99 and $100 \mathrm{~d}$ on experiment. Final live weight was taken as the average of weights recorded on 3 consecutive $d$ immediately before slaughter. Empty body-weight was calculated by subtracting the weight of the contents of the alimentary tract from the live weight recorded just before slaughter. The empty body-weight measure avoids a biased liveweight assessment caused by different weights of alimentary tract contents, which may arise when the diets differ from each other in terms of digestibility, level of intake and rate of passage through the alimentary tract. Carcass-weights were recorded after chilling for $24 \mathrm{~h}$ at $4^{\circ}$. The carcasses were graded by an official grader of the Ministry of Agriculture, Fisheries and Food. 


\section{Rumen fermentation studies}

A mature wether fitted with a rumen cannula was used to assess the pattern of rumen fermentation resulting from feeding each of the basal diets and the Lc $+684 \mathrm{kcal}$ acetate/d diet.

The level of feeding was the same as that of the experimental lambs, and each diet was given for $25 \mathrm{~d}$. On the $21 \mathrm{st}, 23^{\mathrm{rd}}$ and $25^{\text {th }}$ days, strained samples of rumen liquor, approximately $50 \mathrm{ml}$, were taken, using a hand-operated suction pump. The rumen was sampled on four occasions during the day, at 09.00 hours (before feeding), I 1. .00 , I 4.00 and 17.00 hours (before feeding). Immediately after removal of the sample, $\mathrm{pH}$ was recorded to 0.01 units. Each day samples were bulked, taking ro $\mathrm{ml}$ on each sampling occasion, and stored at $-10^{\circ}$. The bulked samples were analysed for total VFA by the method of McAnally (1944) and for the proportions of VFA by the method of Youssef \& Allen (1966). The results are summarized in Table 4.

Table 4. Molar percentage of volatile fatty acids $(V F A)$ in rumen liquor samples taken from one sheep receiving high-concentrate $(H c)$, low-concentrate $(L c)$ or low-concentrate +684 kcalld ( Lc +684 kcal acetate $/ d)$ diets

\begin{tabular}{|c|c|c|c|}
\hline \multicolumn{3}{|c|}{ (Mean values for $24 \mathrm{~h}$ ) } & \multirow[b]{2}{*}{$\begin{array}{l}\mathrm{Lc}+684 \mathrm{kcal} \\
\text { acetate } / \mathrm{d}\end{array}$} \\
\hline & $\mathrm{Hc}$ & Lc & \\
\hline $\begin{array}{l}\text { Total VFA (m-equiv./100 ml) } \\
\text { Acetic acid (molar \%) }\end{array}$ & $\begin{array}{l}10 \cdot 12 \\
64 \cdot 02\end{array}$ & $\begin{array}{l}10.33 \\
73 \cdot 74\end{array}$ & $\begin{array}{l}13 \cdot 07 \\
80 \cdot 81\end{array}$ \\
\hline Propionic acid (molar \%) & 20.91 & $14 \cdot 24$ & $10 \cdot 37$ \\
\hline Butyric acid (molar \%) & $12 \cdot 38$ & $9 \cdot 95$ & $7 \cdot 28$ \\
\hline Valeric acid (molar \%) & $2 \cdot 69$ & 2.06 & $1 \cdot 54$ \\
\hline $\mathrm{pH}$ & 6.50 & $6 \cdot 76$ & $7 \cdot 09$ \\
\hline
\end{tabular}

RESULTS

Values for the initial slaughter group were used to compute average values for the relationships between live weight and empty body-weight, and between live weight and carcass weight at the start of the experiment. Consequently the empty bodyweight and carcass-weight gains made during the experimental period could be estimated. These are shown in Table 5.

In the statistical analysis, results for four lambs were discarded, and a missing plot technique was used to calculate substitute values. Three of these lambs had consistently refused part of the daily ration. One lamb was on $\mathrm{Hc}+684 \mathrm{kcal}$ acetate $/ \mathrm{d}$ treatment and refused concentrate equivalent to $22 \%$ of the intended dry-matter intake and $26 \%$ of acetate supplement, the other lambs were on Lc $+456 \mathrm{kcal}$ acetate $/ \mathrm{d}$ treatments and refused hay equivalent to 7 and $16 \%$ of the intended dry-matter intake. A fourth lamb $(\mathrm{Hc}+228 \mathrm{kcal}$ acetate/d), although consuming the diet offered, developed a progressive debility for which no specific cause was diagnosed.

In the general analysis of variance of the live-weight, empty body-weight and carcass-weight gains made during the experimental period, the responses to acetate in terms of increased weight gains were shown to be highly significant $(P<0.001)$. 
The standard error of this analysis was applied to the mean gains of the two groups of lambs fed the basal unsupplemented diets Hc and Lc. With both diets the liveweight gains were similar, but empty body-weight gain was significantly greater $(P<0.05)$ and carcass-weight gain non-significantly greater on the basal Hc diet.

A partition analysis of treatment sums of squares showed that the live-weight, empty body-weight and carcass-weight gains all gave very highly significant $(P<0.00 \mathrm{I})$ linear regressions. Consequently the gains were directly proportional to the level of acetate supplementation, as illustrated in Fig. I.

Table 5. Treatment means of gains in live weight, empty body-weight and carcass weight (kg) made during the $99 d$ experimental period by groups of six lambs receiving highconcentrate $(H c)$ or low-concentrate $(L c)$ diets with or without supplements of acetate

\begin{tabular}{|c|c|c|c|}
\hline Treatment & $\begin{array}{l}\text { Live-weight } \\
\text { gain }\end{array}$ & $\begin{array}{c}\text { Empty } \\
\text { body-weight } \\
\text { gain }\end{array}$ & $\begin{array}{c}\text { Carcass-weight } \\
\text { gain }\end{array}$ \\
\hline Hc unsupplemented & $6 \cdot 59$ & 7.50 & 5.00 \\
\hline $\mathrm{Hc}+228 \mathrm{kcal}$ acetate $/ \mathrm{d}$ & $8 \cdot 31$ & $8 \cdot 88$ & 5.85 \\
\hline $\mathrm{Hc}+45^{6} \mathrm{kcal}$ acetate $/ \mathrm{d}$ & $I I \cdot 36$ & II 34 & $7 \cdot 24$ \\
\hline $\mathrm{Hc}+684 \mathrm{kcal}$ acetate $/ \mathrm{d}$ & 14.00 & I3.10 & $7 \cdot 95$ \\
\hline Lc unsupplemented & $6 \cdot 68$ & $6 \cdot 36$ & $4 \cdot 18$ \\
\hline $\mathrm{Lc}+228 \mathrm{kcal}$ acetate $/ \mathrm{d}$ & $7 \cdot 78$ & $7 \cdot 42$ & $4 \cdot 8 \mathrm{I}$ \\
\hline $\mathrm{Lc}+456 \mathrm{kcal}$ acetate $/ \mathrm{d}$ & $9 \cdot 31$ & $8 \cdot 75$ & $5 \cdot 19$ \\
\hline $\mathrm{Lc}+684 \mathrm{kcal}$ acetate $/ \mathrm{d}$ & $x 1 \cdot 22$ & 10.31 & $6 \cdot 32$ \\
\hline $\begin{array}{l}\text { Standard error of difference } \\
\text { between means ( } 3 I \mathrm{df} \text { ) }\end{array}$ & 0.47 & 0.48 & 0.41 \\
\hline
\end{tabular}

A further partition analysis of treatment sums of squares was used to determine whether the linear regression relationships between weight gains and level of acetate supplement were different for each of the basal diets. For the relationship between liveweight gain and the level of acetate supplement, the linear regressions were of significantly different slope $(P<0.00 \mathrm{I})$ for the two basal diets. A difference was also apparent in terms of empty body-weight, although at a lower level of significance $(P<0.01)$.

The results relating carcass-weight gains to the supplemented level of acetate produced linear regressions with slopes which were different only at the $P<0.08$ level of significance.

The linear regressions were used to compute the incremental response, over the experimental period of $99 \mathrm{~d}$ to a daily input of $100 \mathrm{kcal}$ energy derived from acetate. These responses are shown in Table 6 .

Carcass grades are not reported, but in general the heavier carcasses graded better. Consequently, of lambs receiving diet $\mathrm{Hc}, 66 \%$ graded A, while only $33 \%$ of lambs receiving diet Lc had grade A carcasses.

\section{DISCUSSION}

For empty body-weight and carcass-weight gains, $1847 \mathrm{kcal}$ of metabolizable energy (ME) supplied by the Hc diet, which produced rumen liquor containing acetic, propionic and butyric acids in the molar proportions $64: 21: 12$, was more 
Vol. 24

efficiently utilized than the same amount of ME supplied by diet Lc, which produced proportions of 74:14:10. This result confirms the findings of Blaxter \& Wainman (I964) and Ørskov \& Allen ( $1966 c$ ). In terms of live-weight gain, the superiority of diet $\mathrm{Hc}$ was masked by the greater weight of gut contents in lambs receiving diet Lc.
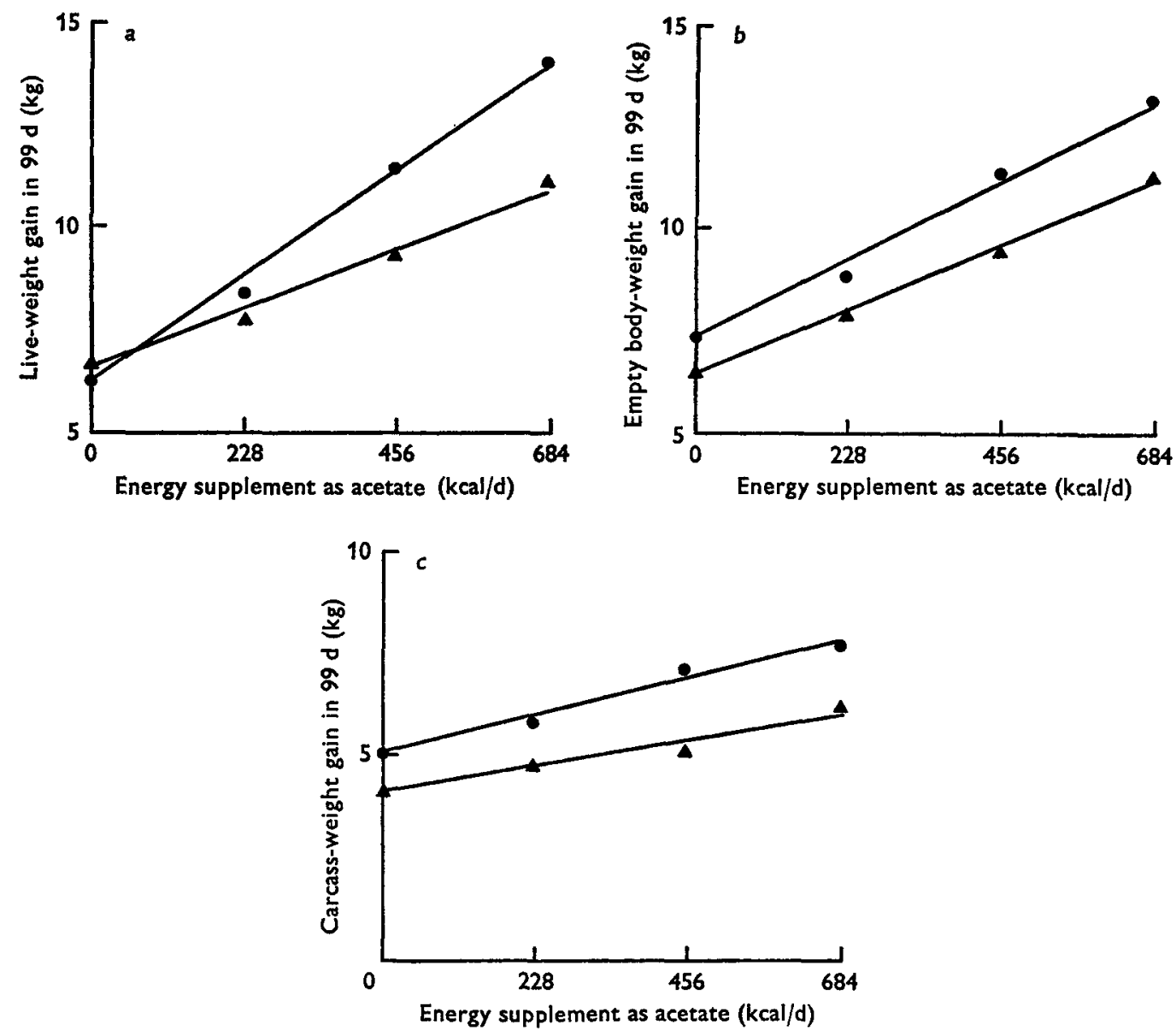

Fig. I. (a) Live weight gains, (b) empty body-weight gains and (c) carcass-weight gains of lambs given high-concentrate $(\boldsymbol{O})$ or low-concentrate $(\boldsymbol{\Lambda})$ diets, some of which were supplemented with acetate. Six lambs per treatment.

Table 6. Calculated mean increments of live weight, empty body-weight and carcass weight $(\mathrm{kg})$ in groups of eighteen lambs, following a supplement of roo kcalld of energy derived from acetate to a high-concentrate or low-concentrate diet over a 99 d experimental period

$\begin{array}{cccc}\text { Diet } & \text { Live weight } & \begin{array}{c}\text { Empty } \\ \text { body-weight }\end{array} & \begin{array}{c}\text { Carcass } \\ \text { weight }\end{array} \\ \text {-concentrate } & \text { I.II } & 0.84 & 0.45^{*} \\ \text {-concentrate } & 0.67 & 0.58 & 0.30^{*}\end{array}$

* These values were calculated using the regression lines of best fit, although in fact the slope of these lines did not differ significantly from each other $(P<0.08)$. 
The basal diets were given in amounts estimated to provide equal intakes of digestible organic matter, with ME intakes calculated on these amounts also being equal. However, this calculation assumes that $\mathrm{ME}$ is a constant proportion of digestible energy, which Blaxter \& Wainman (1964) have demonstrated is not always the case. They showed that the net availability of ME for productive purposes was slightly increased when there was a high proportion of propionic acid in the rumen fermentation. In the experiment reported here, the basal Hc diet resulted in a rumen fermentation with a molar proportion of propionic acid of $21 \%$, while the fermentation from the basal Lc diet produced only $14 \%$ propionic acid. A second factor is that, in order to achieve equal intakes of digestible organic matter with both diets, more of the basal $L c$ diet was given. This higher level of feeding can result in reduced availability of ME from the digestible organic matter (Agricultural Research Council, 1965). Both these factors tend to favour the Hc diet, although they would not be of sufficient magnitude to account for all the observed differences in performance. The remaining difference is probably accounted for by small changes in the efficiency of utilization of ME for maintenance, and larger changes for body gains, according to the dietary concentration of ME (Agricultural Research Council, 1965). The latter effect has been related to the type of rumen fermentation which a diet undergoes, and the utilization of the resultant end-products which are formed (Blaxter \& Wainman, 1964).

This interpretation has been fully discussed by Ørskov \& Allen (1966c) who made a series of experiments in which isocaloric additions of salts of VFA to basal diets of hay and concentrate were utilized with similar efficiencies. They concluded that the lower efficiency of utilization of diets fermented in the rumen to produce high molar proportions of acetic acid might be due to energy losses occurring during the formation of acetic acid rather than during its subsequent utilization. Alternatively, the difference in the efficiency of utilization of high- and low-concentrate diets could be due to differences in the proportions of food digested in the forestomach and hindgut. Bull, Johnson \& Reid (I967) have offered a further explanation, suggesting that the high heat increment of acetic acid recorded in short-term infusion experiments is not maintained over long periods, because metabolic mechanisms adapt to the increased load of acetic acid.

In the present experiment, larger amounts of acetate were given than in previous work, but there was still a linear response to graded supplements of acetate. Even with a daily supplement of $684 \mathrm{kcal}$ energy, sufficient glucogenic material was probably available, since there was no sign of abnormal metabolism. The linearity of the regression extends to the unsupplemented basal diets, indicating a similar efficiency of utilization of ME derived from acetate, produced in the fermentation of the basal diet. It has been assumed that the acetate supplements had no effect on the fermentation of the basal diets (Ørskov \& Allen, I $966 a$ ), but the extent of interconversion of VFA in the rumen (Leng \& Brett, 1966) which may have taken place is unknown. While Bergman, Reid, Murray, Brockway \& Whitelaw (1965) have demonstrated that there is little direct interconversion between propionic and acetic acids, they did show that $6 \mathrm{I} \%$ of butyric acid carbon was in equilibrium with $20 \%$ of acetic acid carbon, and that $2-3$ gram-atoms were interconverted each day. 
The response of live-weight gain to acetate was due both to an increase in carcass weight and to increases in the weight of alimentary tract and its contents (Table 7). The increase in weight of alimentary tract contents was probably linked with the observed increase in water consumption of lambs given acetate. These effects help in the interpretation of the observed differences in efficiency of utilization of acetate when added to the different basal diets. For live-weight gain, acetate was more efficiently utilized when it supplemented the Hc diet $(P<0.00 \mathrm{I})$. This was largely because there were greater increases in weight of alimentary tract and its contents when the Hc diet was supplemented with acetate than when the Lc diet was supplemented. For empty body-weight gain, acetate was again most efficiently utilized when supplementing the $\mathrm{Hc}$ diet, although at a lower level of statistical significance $(P<0.05)$. In this instance there was a greater proportionate increase in the weight of alimentary tract when the Hc diet was supplemented with acetate. With carcassweight gain, the interaction between basal diet and acetate supplementation was not statistically significant, although there was a tendency towards greater gains in lambs fed acetate in conjunction with the Hc diet.

\begin{tabular}{|c|c|c|c|c|}
\hline Level of acetate supplementation (kcal/d) & o & 228 & 456 & 684 \\
\hline $\begin{array}{l}\text { High-concentrate diet: alimentary tract } \\
\text { contents }\end{array}$ & $\begin{array}{l}3 \cdot 28 \\
4 \cdot 19\end{array}$ & $\begin{array}{l}3 \cdot 44 \\
4 \cdot 20\end{array}$ & $\begin{array}{l}3 \cdot 76 \\
5 \cdot 26\end{array}$ & $\begin{array}{l}4 \cdot 17 \\
5.52\end{array}$ \\
\hline $\begin{array}{l}\text { Low-concentrate diet: alimentary tract } \\
\text { contents }\end{array}$ & $\begin{array}{l}3 \cdot 36 \\
5 \cdot 48\end{array}$ & $\begin{array}{l}3 \cdot 45 \\
5 \cdot 61\end{array}$ & $\begin{array}{l}3 \cdot 48 \\
6 \cdot 57\end{array}$ & $\begin{array}{l}3 \cdot 76 \\
6.08\end{array}$ \\
\hline
\end{tabular}

In this experiment there was no estimate of the tissue composition and calorific value of the body gains made by lambs on the different treatments. Elliot, Hogue, Myers \& Loosli (1965) presented evidence which suggested that the carcass gains of lambs fed diets supplemented with isocaloric amounts of acetate or propionate were of similar composition. Since this evidence was based on carcass analysis of only two of the fourteen lambs receiving each treatment, it must be interpreted with some caution.

The results reported here are taken to indicate that the energy of acetic acid was utilized less efficiently when acetate was fed as a supplement to a diet which itself produced a high molar percentage of acetic acid in the rumen. This agrees with the tendency previously noted by Ørskov \& Allen (1966c) in an experiment in which highand low-concentrate diets were supplemented with isocaloric quantities of acetate, propionate or butyrate. They found that whereas the utilization of acetate was better than that of propionate on the high-concentrate diet, it was worse than that of the other acids on the low-concentrate diet. They went on to suggest that their results, and those of Armstrong \& Blaxter (1957) and Armstrong et al. (1958) could indicate that acetic acid concentration can be sufficiently high to cause wasteful oxidation. The ability of metabolic mechanisms to adapt to acetate absorption, as suggested by Bull et al. (1967), may have been exceeded in these experiments. 
We thank S. W. Chubb and F. G. Youssef for providing analytical services, and R. Mead for his helpful advice on the statistics. P. Crowe-Swords and Miss F. E. Hudson are thanked for their skilled technical assistance. The patient co-operation of B.B. and O. Farmers Ltd during feed preparation and A. Meade Ltd during slaughtering is gratefully acknowledged. Distillers Chemicals and Plastics Ltd donated the acetate salts. One of us (D.A.P.) worked during the tenure of a Ministry of Agriculture Postgraduate studentship.

\section{REFERENCES}

Agricultural Research Council (1965). The Nutrient Requirements of Farm Livestock. No. 2. Ruminants. London: H.M. Stationery Office.

Armstrong, D. G. \& Blaxter, K. L. (1957). Br. F. Nutr. II, 4I3.

Armstrong, D. G., Blaxter, K. L., Graham, N. McC. \& Wainman, F. W. (1958). Br. F. Nutr. 12 , 177. Bergman, E. N., Reid, R. S., Murray, M. G., Brockway, J. M. \& Whitelaw, F. G. (I965). Biochem. $\mathscr{J}$. 97, 53.

Blaxter, K. L. \& Wainman, F. W. (1964). F. agric. Sci., Camb. 63, II3.

Bull, L. S., Johnson, D. E. \& Reid, J. T. (I967). Proc. Cornell Nutr. Conf. Feed Mfrs p. 83.

Elliot, J. M., Hogue, D. E., Myers, G. S. Jr \& Loosli, J. K. (1965). F. Nutr. 87, 233.

Great Britain: Parliament (1960). Fertilizer and Feedingstuffs Regulations, 1960. Stat. Instrum. no. I 165. Leng, R. A. \& Brett, D. J. (1966). Br. F. Nutr. 20, 541.

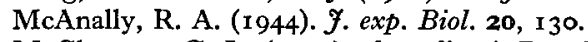

McClymont, G. L. (I952). Aust. F. sci. Res. Ser. B 5, 374.

Ørskov, E. R. \& Allen, D. M. (1966a). Br. F. Nutr. 20, 295.

Ørskov, E. R. \& Allen, D. M. (1966b). Br. F. Nutr. 20, 509.

Ørskov, E. R. \& Allen, D. M. (1966c). Br. F. Nutr. 20, 5 I 9.

Ørskov, E. R., Hovell, F. D. \& Allen, D. M. (1966). Br. F. Nutr. 20, 307.

Youssef, F. G. \& Allen, D. M. (1966). F. Sci. Fd Agric. 17, 536. 